\title{
Moderate Modal Skepticism
}

\author{
Margot Strohminger \\ and \\ Juhani Yli-Vakkuri \\ Humboldt-Universität zu Berlin \\ Universität Bielefeld
}

\begin{abstract}
This paper examines "moderate modal skepticism", a form of skepticism about metaphysical modality defended by Peter van Inwagen in order to blunt the force of certain modal arguments in the philosophy of religion. Van Inwagen's argument for moderate modal skepticism assumes Yablo's (1993) influential world-based epistemology of possibility. We raise two problems for this epistemology of possibility, which undermine van Inwagen's argument. We then consider how one might motivate moderate modal skepticism by relying on a different epistemology of possibility, which does not face these problems: Williamson's (2007: ch. 5) counterfactual-based epistemology. Two ways of motivating moderate modal skepticism within that framework are found unpromising. Nevertheless, we also find a way of vindicating an epistemological thesis that, while weaker than moderate modal skepticism, is strong enough to support the methodological moral van Inwagen wishes to draw.
\end{abstract}

Let us say that an argument is an argument from possibility if and only if at least one of the its premises attributes metaphysical possibility to some state of affairs or other. (Hereafter, unless context makes another reading salient, we will use "possibility", "necessity", "modality" and related words, such as "possible", etc., in the metaphysical senses of these words.)

Arguments from possibility are frequently deployed in many areas of philosophy. Perhaps the most famous example of an argument from possibility is Putnam's (1975) argument for semantic externalism. One of the premises of that argument is that it is possible for there to be both a planet that is in qualitative, intrinsic respects exactly like Earth actually is and another planet (Twin Earth) that is otherwise as similar to the first as a difference in the chemical composition of the stuff that fills the oceans and the lakes permits. Other wellknown examples include Sider's (1993) argument against mereological nihilism, which makes use of the premise that it is possible for there to a physical universe in which every concrete thing has at least one proper part, and Chalmers' (1996) argument against certain varieties of physicalism, which makes use of the premise that it is possible for there to creatures that are physically just as we actually are but that lack consciousness.

The philosophy of religion also features many notable arguments from possibility. In this area we find arguments from possibility whose premises include the following.

(1) It is possible that there is a perfect being.

(2) It is possible that I exist and nothing material exists.

(3) It is possible that something is both concrete and exists necessarily.

(4) It is possible that there is a vast amount suffering without any explanation. 
(1), (2), and (3) have featured in arguments for theism, and (4) in an argument against theism. If the use of arguments from possibility, or of some significant subspecies of them, turned out to be bad philosophical practice, this would be bad news for many areas of philosophy, with the philosophy of religion being no exception.

Some views in the epistemology of modality, alas, threaten to bring us just this bad news. These are views that rule out the possibility - in some alethic but not metaphysical sense $^{2}$ - of our knowing, at least unaided by divine revelation or by the intervention of other superhuman sources of testimony, the possibility-attributing premises of many or all arguments from possibility used in philosophy. The significance of the caveat concerning divine revelation will soon become clear. For now, let us say that to secularly know that $p$ is to know that $p$ without availing oneself of divine revelation or of any testimony from a chain of communication whose original source is a creature with superhuman cognitive capacities. And let us say that the flavor of alethic possibility at issue in the formulation of the various skeptical theses we will discuss is human possibility: roughly, a possibility is (actually ${ }^{3}$ ) a human possibility if and only if it is compossible with the cognitive (and other) capacities of humans being as they actually are. Thus, for example, it is possible, in the intended sense, for us to know that Remain won the 2016 referendum on the UK's membership in the EU (because, even though Remain did not in fact win, it easily could have won, in which case we would have known so using our actual cognitive capacities), but it is not possible, in the intended sense, for any human to know the cut-off point for any sorites-susceptible predicate. (Given classical logic, an omniscient being, of course, would know all such cut-offs.) Thus, to say more briefly what we have already said: certain views in the epistemology of modality rule out the possibility of our secularly knowing the possibility-attributing premises of many or all arguments from possibility used in philosophy.

According to an extreme variety of modal skepticism, whenever it is not the case that $p$, we cannot secularly know that it is possible that $p$. Even this extreme variety of modal skeptic ought to - unless he is a skeptic about non-modal matters as well — grant that, when $p$ obtains and we secularly know that $p$, we can secularly know that it is possible that $p$ by deducing this from $p$. He should also grant that we can often secularly know whether-even if we cannot secularly know that - it is possible that $p$ even when it is not the case that $p$ : for example, if $p$ is a truth-functional contradiction, we can come to know that is not possible that $p$ by deduction alone, in which case we will, of course, know whether it is possible that $p$. Nevertheless, on such a view, our knowledge of possibility, both within and outside of philosophy, is severely limited.

Other, less extreme forms of modal skepticism also appear to threaten much of our philosophically relevant knowledge of possibility. Peter van Inwagen (1977, 1979, 1991, $1995,1998,2006)$ has defended one such view over the course of his career. Because it is supposed to threaten less of our modal knowledge than the extreme view just described, we will call his view moderate modal skepticism. ${ }^{4}$

\footnotetext{
${ }^{1}$ See van Inwagen (1998: 67-69) for (1), (2), and (4) and van Inwagen (1977: 383) for (3).

${ }^{2}$ Metaphysical modality, as we are thinking of it, is the most general alethic modality, of which the others are restrictions. See Williamson $(2017 a$ ) for an introduction to the idea of alethic modality, which Williamson calls "objective modality".

${ }^{3}$ This only works as a characterization of actual human possibility, not as a general characterization of human possibility, because what is humanly possible is a contingent matter, while which states of affairs are compossible is not. Defining the more general notion is a slightly delicate task, which we shall not undertake here because iterated modalities play no role in our discussion.

${ }^{4}$ This label is more informative than van Inwagen's preferred label, "modal skepticism", which he does not seem entirely satisfied with anyway (e.g. 1998: 69).
} 
This paper explores moderate modal skepticism. Moderate modal skepticism is often thought to have the consequence that many arguments from possibility in philosophy are incapable of generating knowledge of their conclusions (\$2). Van Inwagen offers an argument for moderate modal skepticism, which is indebted to Yablo's (1993) influential world-based epistemology of possibility (§3). We raise two problems for the latter epistemology of possibility, which undermine van Inwagen's argument (\$4). We then consider how one might motivate moderate modal skepticism by relying on a different epistemology of possibility, which does not face these problems: Williamson's (2007: ch. 5) counterfactual-based epistemology. We examine three ways of motivating the view. We find two of these unpromising, and we argue that the third one vindicates a weaker epistemological thesis than the one van Inwagen endorses, but nevertheless one that supports the methodological moral he wishes to draw (\$5).

2

Van Inwagen characterizes his skepticism as "the thesis that we are largely ignorant of modal matters that are remote from the concerns of everyday life", and furthermore that we cannot have knowledge of these matters: he affirms "our inability to know what is possible and necessary except in matters closely related to our everyday concerns" (1995: 11).

Alongside the above abstract characterization of his thesis, van Inwagen offers several paradigm cases of the kinds of modal knowledge it rules out. According to van Inwagen (1977: 383, 1998: 70-71), we cannot secularly know whether any of (1)-(4) from $\S 1$ are true. Moreover, some of the possibility-ascribing propositions we are not supposed to be able to secularly know are not 'philosophical' in subject matter (1998: 71), such as the following.

(5) It is possible that that there is "a pure, phenomenal color in addition to red, yellow, green, and blue".

(6) It is possible that there is "a three-inch-thick sheet of solid iron that is transparent to visible light".

(7) It is possible that the laws of physics are different from the actual laws.

This form of modal skepticism is also not supposed to be as extreme as the form which rules out the possibility of secularly knowing that $p$ is possible whenever $p$ is false. Van Inwagen allows that we can know, of a certain table, that it could have been two feet to the left of where it actually is, and that John F. Kennedy could have died of natural causes (1998: 70). Moreover, he allows that we can have knowledge of, or at least reasonable belief in, the possibility of certain states of affairs whose possibility is a philosophically interesting matter (1998: 70). (Presumably Putnam's premise that it is possible that there is a Twin Earth, as described above, is one such, even though it arguably concerns matters "remote from the concerns of everyday life". While it is sometimes unclear-as, in fact, van Inwagen seems to recognize 5 - whether the abstract characterization of his skeptical position lines up with his paradigms, we will set this issue aside until the final section.)

As is standard in discussions of skepticism, the issue is whether it is possible for us to know certain things by relying only on our actual human cognitive capacities. Whether these things can be known by God or some other superhuman being is irrelevant. This is why we have resolved to understand the modal words in "can know", "possible to know", and the like, as expressing human possibility. It is also irrelevant, as van Inwagen (1998: 81, n. 4)

\footnotetext{
${ }^{5}$ In his (1998) Van Inwagen characterizes the view entirely in terms of paradigms.
} 
recognizes, whether it is possible for us to come to know some of these propositions by revelation, even though revelation is (at least in some possible cases) a form of testimony, and the use of testimony in belief formation is a thoroughly ordinary human cognitive capacity. (It is likewise irrelevant whether we can come to know some of these propositions by relying on the testimony of a non-divine superhuman cognizer.) This is why we have consistently used "secularly know" rather than simply "know".

Note that we cannot pack the condition of secularity on knowledge into the restriction on "can" or "-able" in "can know" and "knowable". The reason for this is that it is a matter of contention whether some of the claims targeted by moderate modal skepticism are actually known (van Inwagen himself thinks he knows some of them ${ }^{6}$ ). For example, a moderate modal skeptic who is also a theist and both takes himself to know that God exists and that God is a perfect being will also take himself to know (1), since (1) is logically entailed by these claims. He would not deny that we can know (1), but only that we can secularly know (1). Now suppose that we take the "can" in "can know" to be restricted by the further condition that whatever is known in the accessible possibilities is secularly known. A theist who adopts this restriction on the modal word he uses to express his skeptical thesis and takes himself to know (1) will, absurdly, have to claim that knows some things that he cannot know.

In what follows we shall be concerned exclusively with secular knowledge. To avoid cluttering the discussion, however, we will talk simply of knowledge, where "secular" is left implicit. (Of course, if all knowledge we are capable of having is secular, no such qualification is needed.)

Moderate modal skepticism, at least if its leading advocate is right about the paradigms, has implications for the philosophy of religion. As we have observed, all of (1)(4), or similar possibility claims, have been used as premises of arguments from possibility in this area. For example, Oppy (1995) considers a modal ontological argument involving a premise similar to (1): that it is possible that "there is an entity that possesses maximal greatness", which is to say that it is necessarily "omnipotent, omniscient, and morally perfect" (70). Yablo (1990) discusses the prospects for defending dualism by arguments involving variants on premise (2). (3) is a premise in Plantinga's (1974) ontological argument to which van Inwagen (1977) is responding. A claim similar to (4) is one of the central points of disagreement between Guleserian (1983) and Morris (1987: ch. 3). ${ }^{7}$ If moderate modal skepticism is true, and if it rules out the possibility of knowledge of all of these claims, then the arguments from possibility in which they feature as premises are useless: they cannot be used to extend anyone's knowledge by deduction.

Van Inwagen's main argument for moderate modal skepticism has just two premises. The first premise is that the only method at our disposal for attaining non-testimonial knowledge that it is possible that $p$, when it is not the case that $p$, involves imagining a state of affairs that is appropriately stronger than $p$. (Here van Inwagen follows Yablo's (1993) influential epistemology of possibility.) The second premise is that it is not possible for us to carry out the relevant imaginings for van Inwagen's paradigm cases, and for cases relevantly similar to them. It follows then, that we cannot know any of the paradigmatic or similar possibility claims to be true.

\footnotetext{
${ }^{6}$ Van Inwagen (1995: 11, n. 1) in fact grants this.

${ }^{7}$ See Morris (1987: 48-49), for a description of the scenario that Guleserian takes to be possible and Morris takes to be impossible.
} 
(One peculiar feature of van Inwagen's discussion is that he only discusses possible ways of coming to know that it is possible that $p$ for the paradigm $p \mathrm{~s}$, and yet, as we saw in the previous section, he claims that, in these cases, we cannot know whether it is possible that $p{ }^{8}$ As we observed, one way of coming to know whether it is possible that $p$ is to come to know that it is necessary that it is not the case that $p$. We will not worry about this in what follows, because the main intended application of van Inwagen's moderate modal skepticism is to undermine certain arguments from possibility. As long as we cannot know certain of their premises to be true, we cannot use them to extend our knowledge by deduction.)

Let us now consider, in more detail, the epistemology of possibility that provides the foundation for van Inwagen's argument for moderate modal skepticism. This epistemology is motivated in part by a metaphysical thesis about possibility. That metaphysical thesis is the following equivalence linking possibility to possible worlds:

(Worlds) It is possible that $p$ iff there is a possible world in which (it is the case that) $p$.

The two sides of the material biconditional in (Worlds) are presumed to be more than materially equivalent, although the precise nature of this stronger equivalence is not made explicit. According to van Inwagen:

To assert that $p$ is possible, after all, is to commit oneself, willy-nilly, to the thesis that there is a whole, coherent reality - a possible world — in which $p$ is true, of which the truth of $p$ is an integral part (1998: 77).

Here (Worlds) appears to be used to motivate the following epistemological thesis. In the relevant cases can only come to know a claim of the same form as the left side of (Worlds) either by first coming to know the corresponding claim of the same form as the right side of (Worlds) and then using (Worlds) to infer the former from the latter or by coming to directly know the former by doing whatever is required for knowing the latter. (Why this should be so is an interesting question, to which we will return in $\S 4$.)

How, then, can we come to know that there is a possible world in which it is the case that $p$, in the kind of case envisaged? The idea is that, in order to do so, we have to carry out a certain imagining, which need not involve, although it may involve, visual imagery or otherwise be sensory. ${ }^{9}$ In particular, we must imagine a world in which it is the case that $p$. And imagining a world in which $p$, in turn, requires imagining something stronger than $p$ : it requires imagining that $p$ is true in a certain way, where this way is sufficiently detailed. For example, to imagine a world in which there is a perfect being, it would not be sufficient to simply imagine that there is a perfect being. One must imagine in a certain amount of detail a scenario in which there is a perfect being, in which the perfect being has various non-trivial properties other than that of being a perfect being: for example, being incarnated, or not being incarnated, being identical to Jesus, or not being identical to Jesus, and so on. Only once we have filled in enough details in imagining the scenario, this line of thought goes, have we imagined a world in which there is a perfect being. Call the requirement that we must imagine the scenario in sufficient detail the Specificity Requirement.

So far this is just Yablo's (1993) view. To this van Inwagen adds a further claim about limitations on our imaginative capacities concerning his paradigm cases and ones relevantly similar to them. In particular, he claims that we are unable to imagine the paradigm states of affairs, and ones relevantly similar to them, obtaining in ways that are sufficiently

\footnotetext{
${ }^{8}$ See van Inwagen (1998: 84, n. 17).

${ }^{9}$ See Yablo (1993: 27, n. 55).
} 
detailed for imagining worlds in which these states of affairs obtain. That is, we fail to meet the Specificity Requirement in these cases. He writes:

In my view, we cannot imagine worlds in which there are naturally purple cows, time machines, transparent iron, a moon made of green cheese, or pure phenomenal colors in addition to those we know. Anyone who attempts to do so will either fail to imagine a world or else will imagine a world that only seems to have the property of being a world in which the thing in question exists [...] Can we imagine a world in which there is transparent iron? Not unless our imaginings take place at a level of structural detail comparable to that of the imaginings of condensed-matter physicists who are trying to explain, say, the phenomenon of superconductivity. If we simply imagine a Nobel Prize acceptance speech in which the new Nobel laureate thanks those who supported him in his long and discouraging quest for transparent iron and displays to a cheering crowd something that looks (in our imaginations) like a chunk of glass, we shall indeed have imagined a world, but it will not be a world in which there is transparent iron. (But not because it will be a world in which there isn't transparent iron. It will be neither a world in which there is transparent iron nor a world in which there isn't transparent iron) (van Inwagen 1998: 79).

And similarly, it is claimed, for (1)-(4) and other similar cases. By Yablo's epistemology of possibility, then, it follows that we cannot know (1)-(4), or other relevantly similar possibility claims, to be true.

What should we make of van Inwagen's argument for moderate modal skepticism? We will raise two problems for this argument in the next section, and then go on to look for different arguments for moderate modal skepticism which sidestep this problem.

One rather serious problem with van Inwagen's argument is that the epistemological view it assumes is only motivated to the extent that (Worlds) is, and it is far from clear that (Worlds) is true.

Many philosophers may be surprised to be told that the truth of (Worlds) is far from obvious. After all, many philosophers are accustomed to treating the two sides of the equivalence in (Worlds) as very strictly-perhaps logically-equivalent and to freely substituting modal talk with world talk in their prose in ways that would be licensed by this equivalence. ${ }^{10}$ Nevertheless, it is very unobvious whether (Worlds) is true because it is very unobvious whether there are any possible worlds.

In saying that it very unobvious whether there are any possible worlds we are not making the banal observation that it is very unobvious whether there are 'worlds' as conceived in Lewis's (1986) modal realism. ${ }^{11}$ Lewisian modal realism, as we see it, is not a

\footnotetext{
${ }^{10}$ Unsurprisingly, van Inwagen is one such philosopher: "Although it is in a sense trivial that to assert the possibility of $p$ is to commit oneself to the possibility of a whole, coherent reality of which the truth of $p$ is an integral part, examination of the attempts of philosophers to justify their modal convictions shows that this triviality is rarely if ever an operative factor in these attempts" (1998: 78).

${ }^{11}$ Note that it is unobvious whether there are literally, unrestrictedly, any "worlds" as conceived by Lewis. One might think that the physical universe is one such thing, even if there are no other things of that kind. However, it seems plausible that the universe could have been different from how it actually is in various ways, but no "world", as conceived by Lewis, could have been different from how it actually is, if indeed the claim that a world could have been different from how it actually is is even translatable into Lewis's counterpart-theoretic language. (It seems that the translation, per Lewis (1968), would say that there is a world that is distinct from the actual world but that has a counterpart in the actual world, but in Lewis's (1986) theory no world has a counterpart in any other world.) There is, however, a view in modal metaphysics, which at least one of us tends
} 
theory of modality but an alternative cosmology accompanied by an algorithm for translating our apparently modal language into the non-modal first-order language of that cosmology. We will set modal realism aside and assume, with the mainstream, that, when " $\phi$ " is a sentence, "It is possible that $\phi$ " is a fine way of attributing a property-possibility - to the state of affairs that $\phi$ and not (as Lewis's translation has it) a confused way of making a cosmological claim in whose proper statement " $\phi$ " does not occur at all. ${ }^{12}$

Let us think of possible words in more conventional terms, as maximally possible states of affairs, and let us say that a state of affairs $p$ strictly implies a state of affairs $q$ iff, necessarily, if $p$ then $q$. Following tradition, we define a maximally possible state of affairs in as a state of affairs $p$ that satisfies the condition

(W) Possibly $p$, and, for all $q$, either $p$ strictly implies $q$ or $p$ strictly implies the negation of $q .^{13}$

And let us say that $p$ is true (or obtains) in a world $q$ iff $q$ strictly implies $p$. So understood, (Worlds) says that a state of affairs $p$ is possible iff there is a state of affairs $q$ that satisfies (W) and that strictly implies $q$. If (Worlds) is true, then there must be a state of affairs that satisfies (W). Indeed, there must be very many states of affairs that satisfy (W), since for any two incompossible but individually possible states of affairs, by (Worlds), there are two states of affairs that satisfy (W).

The problem is that it is unclear whether there are any states of affairs that satisfy (W), so it is unclear whether there are any worlds. There are arguments on either side of this issue, which is only beginning to be discussed by philosophers, ${ }^{14}$ but no consensus. We cannot hope to do justice to the dialectic here, but we will briefly discuss one unpromising but well-known argument for the existence of possible worlds, and one more promising and much less well known argument for the same conclusion, along with some reasons to question the argument.

to think is true, according to which there is an entity that has exactly the same parts as the actual universe but that would not have existed if anything at all had gone differently: the view of Hawthorne's (2006) Plenitude Lover, who holds that, for each function from possible worlds - as conceived by the non-modal-realist mainstream - to filled space-time regions in those worlds, there is an object whose parts in a given world are exactly those of the contents of the filled region the function assigns to the world. If this view is correct, then the object corresponding to the function that assigns to the actual world the largest filled space-time region in it and assigns nothing to any other world will be a lot like the "actual world" as conceived by Lewis.

${ }^{12}$ For further discussion of modal realism as cosmology, see Williamson (2014).

${ }^{13}$ The heretical mixture of first and second-order quantification over states of affairs on display here is an inevitable consequence of theorizing about states of affairs in natural language, where we can have variables occurring in sentence position in a quantifier phrase's matrix but not in the quantifier phrase itself: in "some state of affairs $p$ " the variable " $p$ " occurs in the position of an individual variable. Natural language is messy; we follow Williamson and many others in taking the view that, for paradox-avoiding reasons, serious theorizing about states of affairs should be carried out in a higher-order modal language. In second-order modal logic we can define the property of being a possible world in purely logical terms by replacing $(\mathrm{W})$ with

$$
\diamond p \wedge \forall q(\square(p \rightarrow q) \vee \square(p \rightarrow \neg q)),
$$

or, following Prior and Fine (see Fine 1977), with

$$
\diamond(p \wedge \forall q(q \rightarrow \square(p \rightarrow q))
$$

See Williamson $(2003,2013)$ for further advice on how to theorize about states of affairs and other higher-order entities and their modal properties.

${ }^{14}$ There is very little discussion of this issue that we know of outside of folklore. The only example we were able to find in print (which was brought to our attention by Peter Fritz) is Cresswell (2006). Humberstone (1981) expresses some doubts about whether there are possible worlds but does not develop arguments for or against their existence, instead developing a world-free semantics for propositional modal logics. 
The well-known but unpromising argument is a Quine-style abductive "indispensability argument": the assumption that there are possible worlds - and indeed enough of them to make (Worlds) true-is indispensable to our best semantic theories for languages with metaphysical modal operators, and indispensability for the best theories is evidence of truth. ${ }^{15}$ The standard kind of semantics for a language with metaphysical modal operators posits a non-empty set $W$ of entities, ${ }^{16}$ interprets each sentence of the object language (perhaps relative to a variable assignment and some further parameters) as a subset of $W$, and treats "Possibly $\phi$ " as true iff the interpretation of " $\phi$ " is non-empty. If we think of the subsets of $W$ as all of the states of affairs, of strict implication as the subset relation, and of negation as complementation with respect to $W$, we will find that the states of affairs, so conceived, have the right kind of structure to make (Worlds) true. In this setting, (Worlds) translates into the clearly true claim that a $Y \subseteq W$ is non-empty (i.e., possible) iff there is a non-empty $X \subseteq W$ such that, for each $Z \subseteq W$, either $X \subseteq Z$ or $X \subseteq W-Z$. In this setting, the possible worlds turn out to be the singleton subsets of $W$.

This argument rests on a false premise. The assumption that there are entities that behave like possible worlds is, in fact, not indispensable to the best semantics of metaphysical modal language. The established use of "possible worlds semantics", as described above, is largely due to the fame of Kripke's completeness proofs for various systems of modal logic, ${ }^{17}$ which use "possible worlds" as conceived in the previous paragraph. However, logicians have known, at least since since Humberstone $(1979,1981)$ (and, in fact, much longer), ${ }^{18}$ that whatever can be done by "possible worlds' in semantics can also be done in an algebraic semantics in which sentences are interpreted by states of affairs forming a Boolean algebra in which there are no atoms (corresponding to possible worlds). But the converse is not true: the algebraic approach is more general than the "possible worlds" approach, as S. K. Thomason and Kit Fine independently showed in the early 1970 s. ${ }^{19}$

A more serious argument for the existence of worlds-indeed, enough of them to make (Worlds) true - rests on the assumption that, necessarily, for any set of states of affairs $X$, there is a unique conjunction $C(X)$ of the states of affairs in $X$. If we assume further that it is necessary that the conjunction of all states of affairs that obtain is possible, it follows that, necessarily, there is a unique conjunction of all of the states of affairs that obtain and which is a possible state of affairs. Given that it is necessary that, for each state of affairs $p$, the conjunction of all of the states of affairs that obtain either strictly implies $p$ or strictly implies the negation of $p$, it follows, by straightforward modal reasoning, that a state of affairs $q$ is possible iff it is strictly implied by some state of affairs satisfying (W) - i.e., iff it obtains in some possible world, just as (Worlds) says.

This argument, however, rests on a controversial, coarse-grained conception of states of affairs. Suppose that we think of states of affairs-cum-propositions, following David Kaplan and various more recent theorists, ${ }^{20}$ as having structure, so that distinct states of

\footnotetext{
${ }^{15}$ This argument is common in the folklore. Lewis (1986: 19-20) makes a similar argument, although, of course, the "worlds" he posits are not states of affairs.

${ }^{16}$ The members of $W$ are standardly called "worlds", but, as we shall see, the entities that play the role of possible worlds in this style of semantic theorizing are the singletons of the members of $W$.

${ }_{17}$ Beginning with Kripke (1959).

${ }^{18}$ Scroggs (1951) is a notable pre-Kripke example of the use of algebraic semantics to prove the kind of result for which the use of Kripke-style "possible worlds semantics" is now standard. Algebraic semantics for modal logics, however, were known and used as early as the 1930s: see Goldblatt (2003: §3) for a historical survey.

19 See Thomason (1972) and Fine (1974).

20 "If I may wax metaphysical in order to fix an image, let us think of the vehicles of evaluation-the what-issaid in a given context - as propositions. Don't think of propositions as sets of possible worlds, but rather as
} 
affairs may be necessarily equivalent. A suitably fine-grained conception of states of affairs is inconsistent with the assumption, on which the argument rests, that it is necessary that every set of states of affairs has a unique conjunction. For suppose that states of affairs are so fine-grained that, whenever $X$ and $Y$ are distinct sets of states of affairs, $C(X) \neq C(Y)$. Then $C$ would be an injection of the set of all of the sets of states of affairs to the set of all of the states of affairs, which is impossible by Cantor's theorem. ${ }^{21}$

In fact, it is not even clear that friends of coarse-grained states of affairs should accept the argument. It is far from obvious that, necessarily, there is such a thing as the conjunction of all the states of affairs that obtain. And it is a fortiori not obvious why the conjunction of all of the actually obtaining states of affairs should both exist and be possible. One might hope that the existence and possibility of that conjunction would be provable in some way analogous to the way the membership of each consistent sentence in a maximal consistent set of sentences is provable for certain languages, but the analogy breaks down at crucial points, as Cresswell (2006) shows.

One way to further appreciate the difficulty of the issue is by considering the analogy between modality and time. The hypothesis about time analogous to (Worlds) is that a state of affairs sometimes obtains iff it obtains at some instant. ${ }^{22}$ This claim very far from obvious, because it is very unobvious whether there are any points (instants) of time; ${ }^{23}$ it might be that every stretch of time has proper parts. The present issue concerns the structure of modal space and is similarly non-obvious. Our ordinary conception of modality commits us to the existence of regions of modal space-i.e., possible states of affairs - but the truth of (Worlds) requires there to be point-sized regions of modal space. It is fairly clear that nothing in our ordinary conception of modality commits us to any answer to the question of the "pointiness" of modal space. Like the analogous question about the structure of time, whether modal space has a "pointy" structure is a highly theoretical question that must presumably be answered in the way other highly theoretical questions in metaphysics are, not by direct appeal to intuition, and nearly all of the work in this area is yet to be done.

Because the issue of the structure of modal space is only just beginning to be discussed in the literature, and there is no informed consensus on it, we think it is unpromising to base one's epistemology of possibility on (Worlds).

A second problem with the epistemology of possibility on which van Inwagen's moderate modal skepticism relies is that, even if (Worlds) is granted, it is far from obvious why (Worlds) should have the epistemological significance that both Yablo and van Inwagen ascribe to it. For suppose that the two sides of (Worlds) are logically equivalent. It is still unclear why we should posit any epistemological asymmetry between the two sides. And even if, for whatever reason, epistemological asymmetry must be posited, it is unclear why it should not be the converse of what is supposed by Yablo and van Inwagen. That is, it is

structured entities looking something like the sentences which express them" (Kaplan 1977: 494). See Salmon (1986), King (2007), and Soames (2010) for some recent examples of structured-propositions theorizing.

${ }^{21}$ The argument of this paragraph is, of course, derivative of the Russell-Myhill paradox, of which we thank Beau Madison Mount for reminding us in this context. The argument - like the previous paragraph's argument for the existence of worlds - requires the perhaps questionable assumption that there are not too many actual states of affairs to form a set, but if that assumption is false a plural generalization of Cantor's theorem might still get us the reductio we want. See Hawthorne and Russell (forthcoming) for discussion of the relevant Cantorian reasoning for pluralites.

${ }^{22}$ See Fine (1977).

${ }^{23}$ One standard way to characterize instants is to define them analogously with worlds, using second-order quantification and tense operators, following Prior and Fine (see note 13 and Fine 1977). Dorr and Goodman (forthcoming), however, show that this way of defining instants is inconsistent with the plausible view that diamonds are forever (i.e., that impossible states of affairs never obtain). 
unclear why we should not say, instead, that in the relevant cases we can only come to know a claim of the same form as the right side of (Worlds) either by first coming to know the corresponding claim of the same form as the left side of (Worlds) and then using (Worlds) to infer the former from the latter or by coming to directly know the former by doing whatever is required for knowing the latter. In fact, if, as we have supposed, the notion of a possible world is a technical notion defined in terms of the pre-theoretically intelligible notions of possibility and state of affairs, as in (W), it is much more plausible that the epistemological asymmetry is the converse of that posited by Yablo and van Inwagen.

\section{5}

Van Inwagen's own argument for moderate modal skepticism rests on a world-based epistemology of possibility. In the last section we found that epistemology to be undermotivated. In this section we ask whether an alternative epistemology-one that in no way relies on (Worlds) - might be used in support of moderate modal skepticism. ${ }^{24}$ In particular, we will consider Williamson's (2007: ch. 5) epistemology of modality, which takes a different logical equivalence as its starting point: that between "It is possible that $p$ " and "It is not the case that if it were the case that $p$, then it would be the case that $\perp$ " (2007: 157); formally:

(Would) $\diamond p \equiv \neg(p \square \rightarrow \perp)$

(Here " $\perp$ " can be replaced by any truth-functional contradiction, or it can be taken to be a sentence constant that is a truth-functional contradiction; take your pick.)

(Would) is the default view in the logic of counterfactuals. The two standard logics of counterfactuals, Stalnaker's (1968) and Lewis's (1973), both validate it. Furthermore, Williamson (2007: 155-58) shows that (Would) is derivable from independently plausible logical principles concerning the interaction of the metaphysical necessity operator, the metaphysical possibility operator, and the counterfactual conditional. The principles are the following.

(Necessity) $\square(p \rightarrow q) \rightarrow(p \square \rightarrow q)$

(Possibility) $\quad(p \square \rightarrow q) \rightarrow(\diamond p \rightarrow \diamond q)$

And these certainly enjoy a high degree of intuitive plausibility. (Necessity) says, in effect, that strict implication is at least as strong as counterfactual implication, which is difficult to deny-after all, the standard view is that strict implication is stronger than counterfactual implication. (Possibility) says, in effect, that counterfactual implication transmits possibility: any state of affairs counterfactually implied by a possible state of affairs is itself possible. (Would) is derivable from (Necessity) and (Possibility) in the weakest normal modal logic K, so (Would) is at least as plausible as K, (Necessity), and (Possibility). These considerations strongly support the position of (Would) as a secure basis for an epistemology of modality. And they certainly support the view that (Would) is more secure than the highly speculative

\footnotetext{
${ }^{24}$ We expect van Inwagen to be friendly to this kind of exploration, since he is less committed to Yablo's epistemology of possibility than the moderate modal skepticism he wishes to derive from it: "I am inclined to think that if [Yablo's] account is not the whole truth of the matter, it contains a great deal of the truth of the matter, and that the part of it that is right is enough by itself to justify [moderate] modal skepticism" (1998: 81).
} 
(Worlds), which, rather than being derivable from any standard logical commitments, commits its advocates to highly contentious and largely unexamined metaphysical theses. ${ }^{25}$

Like (Worlds), (Would) is an equivalence that does not wear its epistemological significance on its sleeve. However, in the case of (Would) there are convincing reasons for positing an epistemological asymmetry between the two sides. After all, the counterfactual conditional is a thoroughly ordinary notion that is regularly deployed in all areas of inquiry and is indispensable to everyday thought and action, whereas metaphysical possibility is a technical notion that originates in philosophy. It is reasonable to ask for a definition of this notion in ordinary or at least in non-philosophical terms, and such a definition is exactly what (Would) provides. Since we have no independent grasp of the technical notion being defined, the epistemology of the technical notion reduces to that of the ordinary notions in terms of which it is defined. If we follow Lewis and Stalnaker in treating (Would) as a definition, the epistemology of possibility becomes very straightforward: to obtain knowledge of a statement of the same form as the left-hand side of (Would) takes no more and no less than to obtain knowledge of the corresponding statement of the same form as the right-hand side of (Would). This is not to say, of course, that to know that a given state of affairs is possible we must first come to know a certain negated counterfactual, and then use (Would) to infer the possibility of the state of affairs from the negated counterfactual. We rarely perform, at least consciously, such inferences in our modal thinking. A more plausible suggestion, which we adopt, following Williamson, is that any way of coming to know a negated counterfactual whose consequent is a truth-functional contradiction is also way of getting to know the related possibility claim, and that there are no other routes to this knowledge. ${ }^{26}$

One consequence of Williamson's counterfactual-based epistemology of possibility is that skepticism about a certain range of possibility claims is ipso facto skepticism about the corresponding negated counterfactuals. For clearly, given that what we can know is closed under logical consequence, if we cannot know that $p$, and $p$ is logically equivalent to $q$, we also cannot know that $q$. This suggests an obvious strategy for attempting to motivate moderate modal skepticism within the counterfactual-based epistemology of possibility: namely, motivating skepticism concerning the negated counterfactuals that are, by (Would), logically equivalent to the possibility claims whose knowability is denied by the moderate modal skeptic. We will consider three ways of implementing this strategy.

The first way begins with the observation that evolution by natural selection only exerted pressure on us to be reliable in our judgments about a very narrow range of counterfactuals: those whose antecedents are relatively close to actuality, and perhaps furthermore only ones that concern matters over which we have some control. But, this line of thought continues, we have no reason to suppose that our methods of evaluating counterfactuals are reliable outside of that range. Negated counterfactual judgments logically equivalent to van Inwagen's paradigms clearly fall outside of that range. So, we cannot know them.

We find this line of thought to be unpromising. After all, similar evolutionary debunking arguments can be given for any cognitive capacity, leading to rampant skepticism.

\footnotetext{
${ }^{25}$ Nevertheless, some philosophers do deny (Would): Nolan (1997), Dorr (2008), Sider (2011: ch. 12) are notable examples.

${ }^{26}$ Note that this is not to deny, as Williamson does not, that there is no route to knowledge that a state of affairs is possible that does not in some way go via a negated counterfactual. Williamson (2017b) explicitly acknowledges that inferring attributions of metaphysical possibility from restricted alethic modal claims is a way of coming to know those attributions, as recently argued by Strohminger (2015) and Vetter (2017). Rather, the idea is that these other ways of coming to know that a state of affairs is metaphysically possible are also ways of coming to know the logically equivalent negated counterfactual.
} 
Consider, for example, the cognitive capacities we employ in arithmetic. From this perspective, there would be no reason to think that our arithmetical judgments are reliable when they do not concern everyday matters. But clearly we do think that the same cognitive capacities remain reliable when they are applied to judgments about, e.g., large primes. What is missing, and what we doubt can be provided, is some special reason to be skeptical about the counterfactual domain.

The two other ways of attempting to motivate moderate modal skepticism require us to take a closer look at Williamson's counterfactual-based epistemology of possibility. According to Williamson one of the key cognitive capacities we use to evaluate counterfactuals, including those equivalent to attributions of possibility, is the imagination. He characterizes the relevant imaginative exercise as follows.

[B]y [(Would)], we assert $\diamond \mathbf{A}$ when our counterfactual development of the supposition $\mathbf{A}$ does not robustly yield a contradiction (and we do not attribute the failure to a defect in our search); we deny $\boldsymbol{\nabla}_{\mathbf{A}}$ when our counterfactual development of $\mathbf{A}$ robustly yields a contradiction (Williamson 2007: 163).

Williamson describes the process of "counterfactual development" thus:

We can ... schematize a typical overall process of evaluating a counterfactual conditional thus: one supposes the antecedent and develops the supposition, adding further judgments within the supposition by reasoning, offline predictive mechanisms, and other offline judgments. The imagining may but need not be perceptual imagining. All of one's background knowledge and beliefs are available from within the scope of the counterfactual supposition as a description of one's actual circumstances (if we know $\mathbf{B}$, we can infer $\mathbf{A} \square \rightarrow$ (a) B for any A...). Some but not all of one's background knowledge and beliefs are also available within the scope of the supposition as a description of the counterfactual circumstances, according to complex criteria (the problem of cotenability). To a first approximation: one asserts the counterfactual if and only if the development eventually leads one to add the consequent (ibid:: 153).

The second way of attempting to motivate moderate modal skepticism is to claim that in van Inwagen's paradigm cases, and cases that are relevantly similar, however we may try and fail to counterfactually develop the relevant suppositions into contradictions, there will always be a defect in our search, which precludes knowledge of the corresponding attribution of possibility. Suppose, for example, that you counterfactually develop the supposition that there is transparent iron in one way and fail to reach a contradiction. You then do so again and fail to reach a contradiction, and perhaps repeat the exercise in a slightly different way several dozen times. Even when the failure to reach a contradiction is robust, there seems to be no way to rule out the possibility that your search was defective: perhaps you simply did not think far enough; perhaps the contradiction is there to be found, but it would take superhuman powers of imagination to find it. Concluding that no contradiction is counterfactually implied by the supposition that there is transparent iron from the fact that your search for a contradiction failed to turn up a contradiction looks like a bad inductive inference. Concluding that a state of affairs is possible on this basis looks similarly bad to concluding that a theory is consistent by deducing some claims from it and failing to reach a contradiction.

This line of thought, too, we find unpromising. After all, unless we wish to embrace a much more radical form of skepticism concerning both modal and non-modal matters than van Inwagen does, we must accept that inductive inferences sometimes do produce knowledge, and there is nothing very exceptional about the kind of inductive inference 
considered above. Of course not every case in which one tries and fails (no matter how many times) to find a contradiction, whether by deduction or by counterfactual development, is a case in which one is thereby in a position to know that there is no contradiction to be found; but some cases are. Consider deduction. Clearly sometimes we do get to know that a theory is consistent by finding that we were not able to deduce a contradiction from it. In the case of a very simple theory, we may know that if a contradiction could be derived, then it could be derived in a particular way. And in the case of relatively logically complex theories, a long track record of failed attempts at disproof may be powerful evidence of consistencypowerful enough to give us knowledge of consistency. The case of failed attempts to counterfactually develop a supposition into a contradiction does not strike us as relevantly different. Indeed, there is a close relationship between the two that has been known in the literature at least since Lewis's Counterfactuals: an informal proof that $p$ by reductio is a special case of a counterfactual development of the supposition that $\neg p$ into a contradiction. ${ }^{27}$

Furthermore, the second way of attempting to motivate moderate modal skepticism gives us no reason to treat the possibility claims targeted by the moderate modal skeptic differently from others. How, after all, do you know that no contradiction is counterfactually implied by the supposition that JFK died of natural causes? Our counterfactual development of the supposition that JFK died of natural causes does not lead to a contradiction, but anyone sympathetic to the line of reasoning sketched above should also be sympathetic to the idea that a failure (no matter how robust) to find a contradiction in this case does not produce knowledge of possibility. (Perhaps - as Leibniz arguably thought - there is a contradiction to be found even here, but only God, who alone has complete knowledge of the essence or individual concept of JFK, could find it.)

To motivate moderate modal skepticism, we must find a reason for treating counterfactual suppositions concerning "everyday matters" like the JFK example differently from van Inwagen's paradigms. The third and final motivation does provide such a reasonor something close enough - and we suggest that it also provides a partial vindication of van Inwagen's position.

It begins with the observation that the counterfactual-based epistemology of possibility supports something very much like van Inwagen's Specificity Requirement. According to Williamson, in order to deliver knowledge of possibility, the search for a contradiction must be sufficiently thorough. In general one cannot simply suppose that $p$, find that by supposing that $p$ one is not immediately compelled to add a truth-functional contradiction to what one has supposed, conclude on this basis that it is possible that $p$, and thereby come to know that it is possible that $p$. To come to know that it is possible that $p$ by this method, one must imagine, in some detail, how things would be if it were the case that $p$. For example, suppose that $p$ is a mathematical falsehood whose falsity is knowable but not obvious. Then one may have to imagine how things would be if it were the case that $p$ in some detail, adding various further mathematical truths to what one imagines, and taking many inferential steps, before one reaches a contradiction.

Furthermore, it seems plausible to us - although Williamson does not say this-that, at least generically speaking, the more distant a state of affairs $p$ is from actuality, the more difficult it will be to imagine how things would be if $p$ were to obtain in the amount of detail required for knowing that $p$ does not counterfactually imply a contradiction. Consider a state of affairs that is very close to actuality - say, that you drink one more cup of coffee today than you actually do. It is easy to imagine how things would be if that state of affairs obtained

\footnotetext{
${ }^{27}$ See Yli-Vakkuri (2013: 611), which cites Lewis (1973). Note that, according to the counterfactual-based epistemology, an informal proof by reductio also establishes the necessity of the claim that has been proved.
} 
in great detail, because we can largely hold what we know about the actual state of affairs fixed in our imagination: we will imagine that the laws of nature are as they actually are, that national borders are where they actually are, that the building you are in is made of the materials it actually is, and so on. The known facts we properly hold fixed are those that are, to use Goodman's (1954) term, cotenable with the counterfactual supposition. The more distant the counterfactual supposition is from actuality the fewer of the actual facts are cotenable with it. Massive departures from actuality still need not paralyze our capability for counterfactual development. For example, although Max Black's (1952) universe containing only two duplicate metal spheres orbiting each other is a very distant possibility, we can imagine in some detail how things would be if that possibility obtained, because in doing so we hold the actual laws of nature fixed, and we know quite a lot about how such metal spheres would behave if the actual laws of nature obtained. Counterfactual development, however, gets much more difficult when we consider departures from the actual laws of nature and universes in which alien fundamental properties are instantiated, such as Sider's (1993) "gunky" universe. How are we to fill in the details of how a gunky universe would work? Which laws of nature should we imagine to hold? The license to hold various regularities that actually obtain fixed in counterfactual development gives us a pretty good purchase on what is and isn't cotenable with a counterfactual supposition. When virtually all of these, beyond logical and mathematical facts, go by the wayside, judgments of cotenability become much more difficult. Williamson himself is open to this possibility:

A nuanced account of our handling of counterfactuals is likely to predict that we are more reliable in evaluating some kinds than others. For example, we may well be more reliable in evaluating counterfactuals whose antecedents involve small departures from the actual world than in evaluating those whose antecedents involve much larger departures. We may be correspondingly more reliable in evaluating the possibility of everyday scenarios than of "farout" ones, and extra caution may be called for in the latter case. At the limit, actuality is often the best argument for possibility (Williamson 2007: 164).

A related observation: the closer we get to actuality - especially when we get very close - the less need there is to use counterfactual development to resolve questions of possibility. Close to actuality we have other methods at our disposal. Above Williamson points out the limit case: when $p$ is actual, we can often come to know that $p$ by a variety of other methods, and then infer from $p$ that it is possible that $p$. But even when $p$ is not an actual state of affairs but is close to actuality, other methods will often be available. For example, it is very close to actuality that this cup, which does not in fact break, breaks, and one can see (know by vision) that the cup is breakable, and then deduce from this the weaker alethic modal claim that it is metaphysically possible that the cup breaks. ${ }^{28}$

It appears, then, that within the counterfactual-based epistemology of possibility, distance from actuality matters approximately in the way distance form concerns of everyday life does according to van Inwagen's account. The more distant a state of affairs is from actuality, the more need there is for us to be able to imagine how things would be if the state of affairs obtained in some detail (when we are close to actuality, other methods are available), and the less able we are to imagine it at a level of detail required for knowledge of possibility.

Note, however, that distance from actuality does not quite coincide with distance from concerns of everyday life, so we cannot draw the conclusion that distance from concerns of everyday life matters in the way van Inwagen thinks it does. Many actual states of affairs,

\footnotetext{
${ }^{28}$ See Strohminger (2015).
} 
which, being actual, are as close to actuality as any state of affairs can be, are distant from the concerns of everyday life. To take an obvious kind of example, let $p$ be any state of affairs that does not obtain and is unrelated to the concerns of everyday life; then either $\diamond p$ or $\neg \diamond p$ actually obtains, so is maximally close to actuality, but since $p$ itself is unrelated to concerns of everyday life, so, presumably, are both $\diamond p$ and $\neg \diamond p$. It might be suggested that when $p$ is non-modal (whatever that means exactly) and false the difficulty of knowing that $\diamond p$ increases with the distance of $p$ from the concerns of everyday life. There may be something to this thought, but if so it is at best a rough generalization that permits many exceptions. ${ }^{29}$ After all, science textbooks provide many examples of states of affairs that do not obtain and are very remote from the concerns of everyday life, yet that can be known to be nomologically and therefore metaphysically possible. Quantum mechanics and statistical mechanics are particularly rich sources of such examples, as Hawthorne (2005) and Hawthorne and Lasonen-Aarnio (2009) point out.

The above considerations support the view that Inwagen's paradigmatic possibility claims - and others similarly distant from actuality, although not necessarily all others similarly remote from the concerns of everyday life - are more difficult to know than various possibility claims that concern "everyday matters". One could also take them to support the methodological conclusion van Inwagen draws: perhaps the relevant possibility claims are so difficult to know that debates concerning their truth are not fruitful and are best abandoned. But it is still not clear why they should support moderate modal skepticism itself-even a version of it that replaces "distance from the concerns of everyday life" with "distance from actuality". According to either version the paradigms are unknowable. But many facts are difficult to know, yet knowable.

Alongside moderate modal skepticism, van Inwagen also endorses, unsurprisingly, an attitude of "epistemic humility" in modal matters that are "unrelated to the concerns of everyday life". ${ }^{30}$ One does not have to be any kind of modal skeptic to endorse something in the vicinity of this attitude, which is also supported by the counterfactual-based epistemology of modality - although, for reasons discussed two paragraphs ago, replacing "unrelated to the concerns of everyday life" with "distant from actuality" results in a more plausible suggestion. An attitude of epistemic humility, however, seems to us at least as warranted in the epistemology of modality, when it comes to the knowability of the possibility of states of affairs that are distant from actuality. While we have good evidence that many possibility claims of interest to philosophers, including van Inwagen's paradigms, are difficult to know, we think that epistemic humility should also rein in the temptation to conclude that those claims are unknowable.

Acknowledgments. We would like to thank Kit Fine, Peter Fritz, John Hawthorne, Beau Madison Mount, and Jeff Speaks for helpful discussions and comments.

\footnotetext{
${ }^{29}$ The claim that, generally, the difficulty of knowing $\diamond p$ increases with $p$ 's distance from actuality also allows some exceptions. Suppose that $p$ is possible and distant from actuality, and it is difficult to know $\diamond p$. Then it is at least as difficult to know $\diamond \diamond p$, even though $\diamond p$ is maximally close to actuality.

${ }^{30}$ Van Inwagen (1991: 151).
} 


\section{References}

Black, M. 1952. “The identity of indiscernibles', Mind 61: 153-64.

Chalmers, D. J. 1996. The Conscious Mind: In Search of a Fundamental Theory. Oxford: Oxford University Press.

Cresswell, M. J. 2006. "From modal discourse to possible worlds", Studia Logica 82: 307-27.

Dorr, C. 2008. "There are no abstract objects", in Contemporary Debates in Metaphysics, edited by T. Sider, J. Hawthorne, and D. W. Zimmerman, 32-63. Oxford: Blackwell.

Dorr, C. and J. Goodman (forthcoming). "Diamonds are forever", Nô̂s.

Fine, K. 1974. “An incomplete logic containing S4", Theoria 40: 23-29.

Fine, K. 1977. "Postscript: Prior on the construction of possible worlds and instants", in Prior and Fine 1977: 116-68.

Goldblatt, R. 2003. "Mathematical modal logic: A view of its evolution”, Journal of Applied Logic 1: 309-92.

Goodman, N. 1954. Fact, Fiction, and Forecast. Cambridge, MA: Harvard University Press.

Guleserian, T. 1983. "God and possible worlds: The modal problem of evil", Noûs 17: 221-38.

Hawthorne, J. 2005. "Chance and counterfactuals", Philosophy and Phenomenological Research 70: 396-405.

Hawthorne, J. 2006. "Plenitude, convention, and ontology", in Metaphysical Essays. Oxford: Oxford University Press.

Hawthorne, J. and M. Lasonen-Aarnio. 2009. "Knowledge and objective chance", in Williamson on Knowledge, edited by P. Greenough and D. Pritchard, 92-108. Oxford: Oxford University Press.

Hawthorne, J and J. Russell (forthcoming). "Possible Patterns", Oxford Studies in Metaphysics.

Humberstone, L. 1979. "Interval semantics for tense logic: Some remarks", Journal of Philosophical Logic 8: 171-96.

Humberstone, L. 1981. "From worlds to possibilities", Journal of Philosophical Logic 10: 313-39.

Kaplan, D. 1977. "Demonstratives”, in Themes from Kaplan, edited by J. Almog, J. Perry, and H. Wettstein, 481-563. Oxford: Oxford University Press, 1989. Completed and circulated in mimeograph in the published form in 1977. Page references to the former.

King, J. C. 2007. The Nature and Structure of Content. Oxford: Oxford University Press.

Kripke, S. 1959. "A completeness theorem in modal logic”, Journal of Philosophical Logic 24: 1-14.

Kripke, S. 1980. Naming and Necessity. Oxford: Blackwell.

Lewis, D. K. 1968. "Counterpart theory and quantified modal logic”, Journal of Philosophy 65: 113-26.

Lewis, D. K. 1973. Counterfactuals. Oxford: Basil Blackwell.

Lewis, D. K. 1986. On the Plurality of Worlds. Oxford: Blackwell.

Morris, T. V. 1987. "The necessity of God's goodness", Anselmian Explorations: Essays in Philosophical

Theology, 42-69. Notre Dame, IN: University of Notre Dame.

Nolan, D. 1997. "Impossible worlds: A modest approach", Notre Dame Journal of Formal Logic 38: 535-73.

Oppy, G. 1995. Ontological Arguments and Belief in God. Cambridge: Cambridge University Press.

Plantinga, A. 1974. The Nature of Necessity. Oxford: Clarendon Press.

Prior, A. N., and K. Fine. 1977. Worlds, Times, and Selves. London: Duckworth.

Putnam, H. 1975. "The meaning of 'meaning'”, Minnesota Studies in the Philosophy of Science 7: 131-93.

Salmon, N. U. 1986. Frege's Puzzle. Cambridge, MA: MIT Press.

Scroggs, S. J. 1951. "Extensions of the Lewis system S5", Journal of Symbolic Logic 16: 112-20.

Sider, T. 1993. "Van Inwagen and the possibility of gunk", Analysis 53: 285-89.

Sider, T. 2011. Writing the Book of the World. Oxford: Oxford University Press.

Soames, S. 2010. What is Meaning? Princeton, NJ: Princeton University Press.

Stalnaker, R. 1968. "A theory of conditionals", in Studies in Logical Theory, edited by N. Rescher, 98-112. Oxford: Blackwell.

Stalnaker, R. 2012. Mere Possibilities: Metaphysical Foundations of Modal Semantics. Princeton, NJ: Princeton University Press.

Strohminger, M. 2015. "Perceptual knowledge of nonactual possibilities", Philosophical Perspectives 29: 36375.

Thomason, S. K. 1972. "Noncompactness in propositional modal logic", Journal of Symbolic Logic 37: 716-20. van Inwagen, P. 1977. “Ontological arguments”, Noûs 11: 375-95.

van Inwagen, P. 1991. "The problem of evil, the problem of air, and the problem of silence", Philosophical Perspectives 5: 135-65. Reprinted in van Inwagen 1995.

van Inwagen, P. 1995. God, Knowledge, and Mystery. Ithaca, NY: Cornell University Press. van Inwagen, P. 1998. "Modal epistemology”, Philosophical Studies 92: 67-84.

van Inwagen, P. 2006. The Problem of Evil. Oxford: Oxford University Press.

Vetter, B. 2017. "Williamsonian modal epistemology, possibility-based", in Yli-Vakkuri and McCullagh 2017. Williamson, T. 2003. "Everything”, Philosophical Perspectives 17: 415-65. 
Williamson, T. 2007. The Philosophy of Philosophy. Oxford: Blackwell.

Williamson, T. 2013. Modal Logic as Metaphysics. Oxford: Oxford University Press.

Williamson, T. 2014. "Replies to Bricker, Divers, and Sullivan", Philosophy and Phenomenological Research 88: 744-64.

Williamson, T. 2017a. "Modal science", in Yli-Vakkuri and McCullagh 2017.

Williamson, T. 2017b. "Reply to Vetter", in Yli-Vakkuri and McCullagh 2017.

Yablo, S. 1990. "The real distinction between mind and body", Canadian Journal of Philosophy 16: 149-201.

Yablo, S. 1993. "Is conceivability a guide to possibility?", Philosophy and Phenomenological Research 53: 142.

Yli-Vakkuri, J. 2013. "Modal skepticism and counterfactual knowledge,” Philosophical Studies 162: 605-23.

Yli-Vakkuri, J. and M. McCullagh, eds. (2017). Williamson on Modality. London: Routledge. 